\title{
Influence of Particle and Grain Size on Sand Filtration: Effect on Head Loss and Turbidity
}

\author{
Racha Medjda Bouchenak Khelladi (Corresponding Author) \\ Laboratory of Valorisation of Water Ressources (V.R.E), University of Tlemcen, Faculty of \\ Technology, BP 119, 13000, Tlemcen-Algeria \\ E-mail: rashamajda@hotmail.fr
}

\begin{abstract}
Abdelghani Chiboub Fellah
Laboratory of Valorisation of Water Ressources (V.R.E), University of Tlemcen, Faculty of Technology, BP 119, 13000, Tlemcen-Algeria

E-mail: chibabghani@yahoo.fr
\end{abstract}

\begin{abstract}
Maxime Pontié
University of Angers, Faculty of Sciences, Department of Chemistry, 2 bd Lavoisier, Angers 49045 cedex 01, France.

E-mail: maxime.pontie@univ-angers.fr
\end{abstract}

Fatima Zohra Guellil

University of Tlemcen, Faculty of Sciences, Department of Chemistry, BP 119, 13000, Tlemcen-Algeria

E-mail: cfatema@yahoo.fr

Received: July 14, 2020 Accepted: August 5, 2020 Published: August 11, 2020

doi:10.5296/ast.v8i2.17512 URL: https://doi.org/10.5296/ast.v8i2.17512

\begin{abstract}
Sand filtration is an eco-friendly method to treat either drinking water or wastewater; it requires only natural granular media. It is also easy to use and to maintain; the only problem they face is clogging that affects filter performance, that can be detected when head loss or turbidity increase. The purpose of this work is to see what are the factors that influence the
\end{abstract}


performance of filter operation, for this, we used a pilot consisting on a circular column filled with sand (from South Algeria), where various parameters were tested; pressure, flow rate, sand granulometry, suspended matters and particle concentration of the water which is filtered. After eighteen weeks of operation, we have found that head loss increases by decreasing granulometry and increasing flow rate, pressure, particle size, and concentration. However, turbidity increases by decreasing particle size and increasing granulometry and particle concentration. Turbidity and head loss have different behaviour towards the same parameter; that is why it is necessary to take them into account in order to find a compromise between acceptable head loss / turbidity for a good functioning of the filter.

Keywords: head loss, turbidity, filtration, sand, granulometry

\section{Introduction}

In the drinking water supply and wastewater, many pollutants are particles or are associated with particles. Therefore, particle removal is one of the main goals of water treatment.

Sand filtration is the oldest way to treat drinking water and has become more popular for domestic wastewater treatment because of its efficiency, ease of maintenance, and limited energy costs. It requires a few technical components and usually no chemical products are used. Filtration is a process of purifying water in which water passes through a porous sand bed containing a biological film that traps and metabolizes organic compounds in water, which is very effective on removing bacteria, organic matter, cysts, eggs, and viruses are effectively removed from the filtered water (Aloo B.N. et al., 2014).

Suspended solids are physically removed by straining. The retained organic carbon pollutants undergo hydrolysis and are biologically degraded under the aerobic reactions of heterotrophic bacteria (Rodgers M. et al., 2005).

Filtration generally works until the head loss across the filter bed becomes excessive, or the capacity of the bed to remove suspended solids at the desired effluent quality is impaired (Tansel B. \& Vilar F., 2005). That is engendered by the permeability reduction caused by the particles deposition in porous media, and produces a clogging (Mays C.D. \& Hunt J.R., 2005), which can have an effect on the head loss as well as on the water turbidity variation at the outlet of the filter.

Although the impact of media size on filter performance largely depends on the particle size distribution and surface chemistry of particulate matter in source water (Ephrem G., 2015). The aim is to see how the filter's performance in terms of head loss and turbidity, is influenced by the operating filter's parameters.

\section{Material and Method}

\subsection{Pilot Description}

The filtration pilot TE 400 (figure 1) manufactured by DELTALAB, consists of a transparent, cylindrical Policloreto de vinila (PVC) feed tank with a working capacity of $150 \mathrm{~L}$ with a drain valve DN 10; a filtration column of altuglas with $100 \mathrm{~mm}$ internal diameter and 1000 


\section{Mll Macrothink}

$\mathrm{mm}$ height and two brass support and stop grids with a mesh of $0.5 \mathrm{~mm}$; two manual adjustment valves, one for setting the input flow VR2 and one for setting the output or filtrate flow rate. Both valves are DN 10; twelve piezometric multitubes for measuring the pressure in the filter column at different heights, in altuglas, $8 \mathrm{~mm}$ diameter, $500 \mathrm{~mm}$ height; a float flowmeter with a maximum flow rate of $200 \mathrm{~L} \cdot \mathrm{h}^{-1}$ of the filtrate outlet of the transparent PVC column DN 10; variable scale from 20 to $200 \mathrm{~L}^{-h^{-1}}$ with a $\pm 5 \%$ precision; a feed pump of the suspension and four manual valves, VA1 for the manifold multi-manometer isolation, VA2 for the multi-gauge bicycle pump stop, VA3 for the backflow stop, VA4 for shutdown venting and VD1 for top distribution of the filter; a manometer for measuring the pressure.

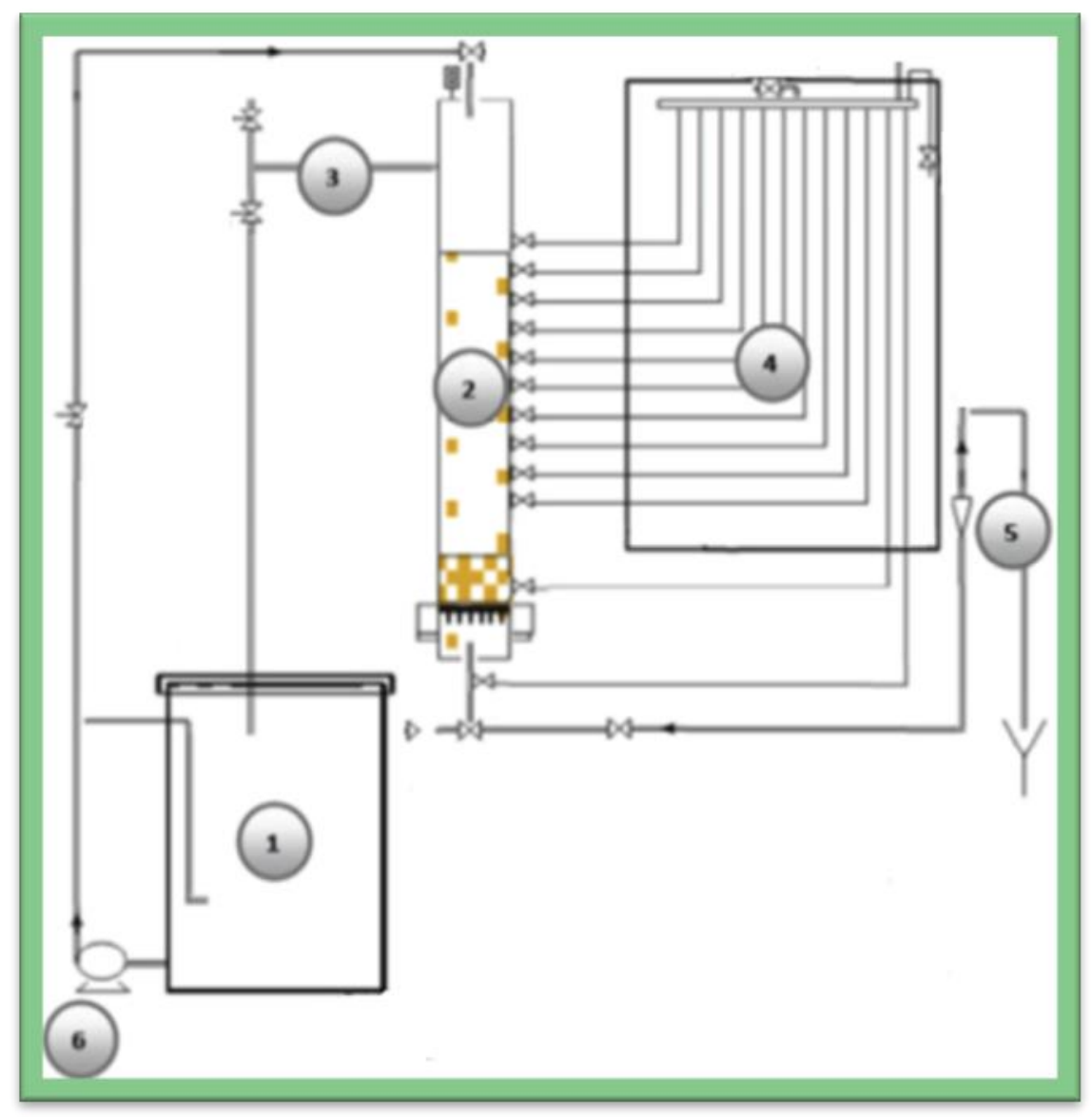

Figure 1. Pilot TE400

\subsection{Filter Media}

The particle size analysis (granulometry) gives important information on the filter medium used for this study. The particle size analysis was carried out according to Standard NF EN 933-1 (Afnor, 1997), which consists of passing a quantity of the sample through a succession of sieves with decreasing diameters opening by applying vibrations. Two other parameters were determined according to Liénard A. et al. (2001) such as volumic mass ( $\rho$ ), and density (d).

For our study, we used three different types of sand from south Algeria, their characteristics are in table 1 . The height of the sand bed is $50 \mathrm{~cm}$ for the three types of sand. 
Table 1. Caracteristics of the used sands

\begin{tabular}{l|l|l|l|l|l}
\hline & $\mathbf{D}_{\mathbf{E}}(\mathbf{m m})$ & $\mathbf{D}_{\mathbf{6 0}}(\mathbf{m m})$ & $\mathbf{C}_{\mathbf{U}}$ & $\boldsymbol{\rho}\left(\mathbf{k g} / \mathbf{m}^{\mathbf{3}}\right)$ & $\mathbf{d}$ \\
\hline $\mathbf{S a n d ~}^{\circ} \mathbf{1}$ & 0.73 & 1.4 & 1.91 & 2857.14 & 2.85 \\
\hline $\mathbf{S a n d ~}^{\circ} \mathbf{2}$ & 0.56 & 1.42 & 2.53 & 2564.1 & 2.56 \\
\hline $\mathbf{S a n d ~}^{\circ} \mathbf{3}$ & 0.97 & 1.41 & 1.45 & 2777.77 & 2.77 \\
\hline
\end{tabular}

$\mathbf{D}_{\mathbf{E}}$ : Effective diameter, where $10 \%$ of the weight of sand is less than $\mathrm{D}_{\mathrm{E}}$

$\mathbf{D}_{60}: 60 \%$ of the weight of sand is less than $\mathrm{D}_{60}$

Cu: Uniformity coefficient, calculated by the ratio $\mathrm{D}_{60}$ and $\mathrm{DE}_{\mathrm{E}}$

\subsection{Filtration Procedure}

The filtration pilot is fed with a synthetic water from the tank (14) with a filtration rate of 30 L.h ${ }^{-1}, 50$ L.h ${ }^{-1}, 80$ L.h ${ }^{-1}, 120$ L.h ${ }^{-1}, 150$ L.h ${ }^{-1}$ corresponding to filtration velocities $3.82 \mathrm{~m} . \mathrm{h}^{-1}$, $6.36 \mathrm{~m} . \mathrm{h}^{-1}, 10.19 \mathrm{~m} . \mathrm{h}^{-1}, 15.28 \mathrm{~m} \cdot \mathrm{h}^{-1}$, and $19.1 \mathrm{~m} . \mathrm{h}^{-1}$ respectively. Those velocities show that the filtration is categorized as rapid filtration because it is greater than $0.3 \mathrm{~m} / \mathrm{h}$ (Campos, $\mathrm{L}$. C., et al., 2002)

To study the influence of the concentration and the type of suspended matters on the filtration, six suspensions of synthetic water were prepared with tap water at the laboratory, e.g, three bentonite samples and three lime samples with an increasing concentration of 0.1 g. $\mathrm{L}^{-1}, 0.3$ g. $\mathrm{L}^{-1}$ and $0.5 \mathrm{~g} . \mathrm{L}^{-1}$.

Two valves VA4 (3) and VA3 (8) position were tested to study the influence of pressure on the filtration.; the first one, the two valves VA4 and VA3 open (VA4O, VA3O), and the second one, the valve VA4 closed and VA3 open (VA4F, VA3O).

For the water heights in the filtration column, it has been maintained at $35 \mathrm{~cm}$ above the filter media. This water level is situated above the inlet of the pipe return feed tank which is readjusted by the valve VA3 (maintained open in the whole experiment) and allows to excess water to return to the feed tank, all with the aim of better managing the pressure at the filter and not damaging the pilot.

The study was carried out during eighteen weeks, where the sand filter is fed for 5 hours a day with a changing flow rate each hour. We worked five times a week, 5 days/7, and therefore a daily volume of $150 \mathrm{~L}$ which is the useful capacity of the feed tank. Filtration was carried out for the three types of sand, the five flow rates, the six synthetic water samples, and the two valve positions.

The filtration procedure is shown in table 2 for only sand $\mathrm{N}^{\circ} 1$, which takes 6 weeks. The flow rate was readjusted each hour, and the valves position was readjusted after one week and half. The same procedure has been followed for sand $\mathrm{N}^{\circ} 2$ and sand $\mathrm{N}^{\circ} 3$. 
Table 2. Filtration procedure for sand $\mathrm{N}^{\circ} 1$

\begin{tabular}{|c|c|c|c|c|c|c|c|c|}
\hline Weeks & 1 & 2 & & & 4 & \multicolumn{2}{|l|}{5} & 6 \\
\hline Sand & \multicolumn{8}{|c|}{ Sand $N^{\circ} 1$} \\
\hline Suspended matter & \multicolumn{4}{|c|}{ Bentonite } & \multicolumn{4}{|c|}{ Lime } \\
\hline Concentration g. $\mathrm{L}^{-1}$ & 0.1 & 0.3 & & 5 & 0.1 & 0.3 & & 0.5 \\
\hline Flow & \multirow{2}{*}{\multicolumn{4}{|c|}{$30,50,80,120,150$}} & \multirow{2}{*}{\multicolumn{4}{|c|}{$30,50,80,120,150$}} \\
\hline $\mathbf{L} \cdot \mathbf{h}^{-1}$ & & & & & & & & \\
\hline Valves position & $\mathrm{P} 1$ & $\mathrm{P} 1$ & $\mathrm{P} 2$ & $\mathrm{P} 2$ & $\mathrm{P} 1$ & $\mathrm{P} 1$ & $\mathrm{P} 2$ & $\mathrm{P} 2$ \\
\hline
\end{tabular}

P1 : VA3O, VA4O P2 : VA3O,VA4F

\subsection{Filter Washing Procedure}

The head losses are an important indicator of filter performance which determines the operating time of a filter (Davies P.D., 2012), in our study we get interested in the variation of the head losses and the turbidity at the filter outlet to start the washing by a backward flow water injection.

\subsection{Sampling and Analysis}

Samples are taken from the feed tank (synthetic water) and at the filter outlet (after filtration) for the three sand types with the five flow rates and the six different suspensions of synthetic water to measure their turbidity using a HANNA HI 93703 turbidimeter.

Throughout the filtration, the head losses were measured by a reading on the twelve piezometers, knowing that the piezometers give a minimum value of head loss of $30 \mathrm{~cm}$ and a maximum value of head loss of $-30 \mathrm{~cm}$.

The samples, as well as the reading on the piezometers, were carried out after every 15 minutes, required time for the stabilization of the piezometric level and obtaining of steady-state flow conditions.

Figure 2 presents a summary of the whole experiment, and how it has been carried out. 


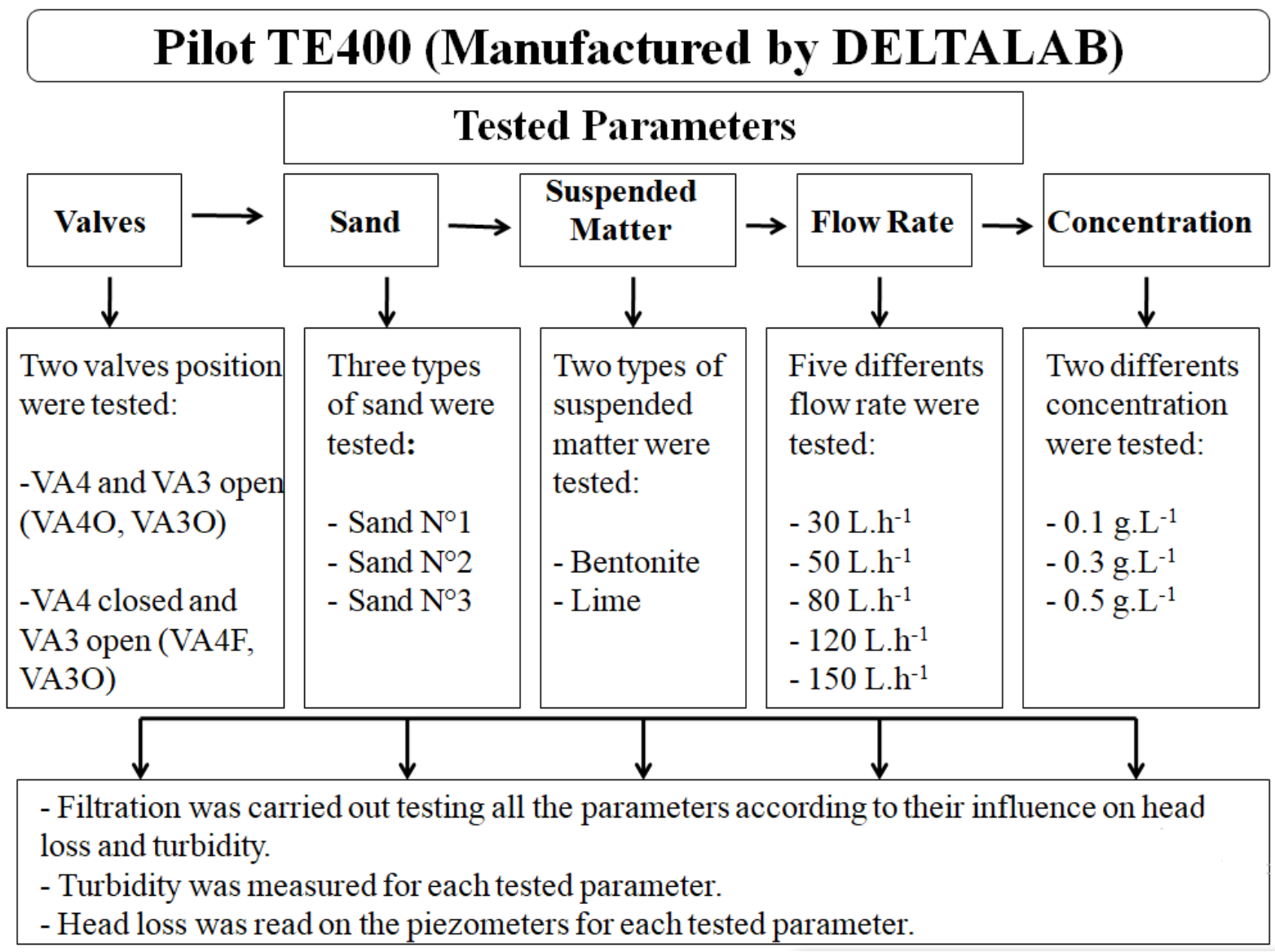

Figure 2. Summary of the steps followed in the experiment

\section{Results and Discussion}

\subsection{Evolution of the Head Loss}

The head losses are affected by the accumulation of solids in the filter bed during the filtration, how the retention of these solids influence on the head losses is determined by the media filter retention capacity as well as the particle size, and the biggest operational problem is the clogging phenomenon due to surface deposition (Davies P.D., 2012). The determination of the clogging time allows us to predict when the filter will no longer be useful because of flow or efficiency reduction of the filter.

\subsubsection{Influence of the Pressure}

It has been found (figure 3 ) that for all the studied parameters, it is the position of the valves VA3O (VA3 open) and VA4O (VA4 open), which gives the lowest head loss and VA3O (VA3 open) and VA4F (VA4 closed) gives the highest head loss. When the two valves VA3 and VA4 are open there is a setting atmosphere (atmospheric pressure) however when one of the two valves is closed the pressure within the column is greater than the atmospheric pressure which increases the head losses, therefore, at higher pressures, clogging occurs more rapidly (Wyss et al., 2006). Particle transport on the media surface is driven by inertial forces, Brownian motion, sedimentation, and interception (Georgieva K. et al., 2010). 


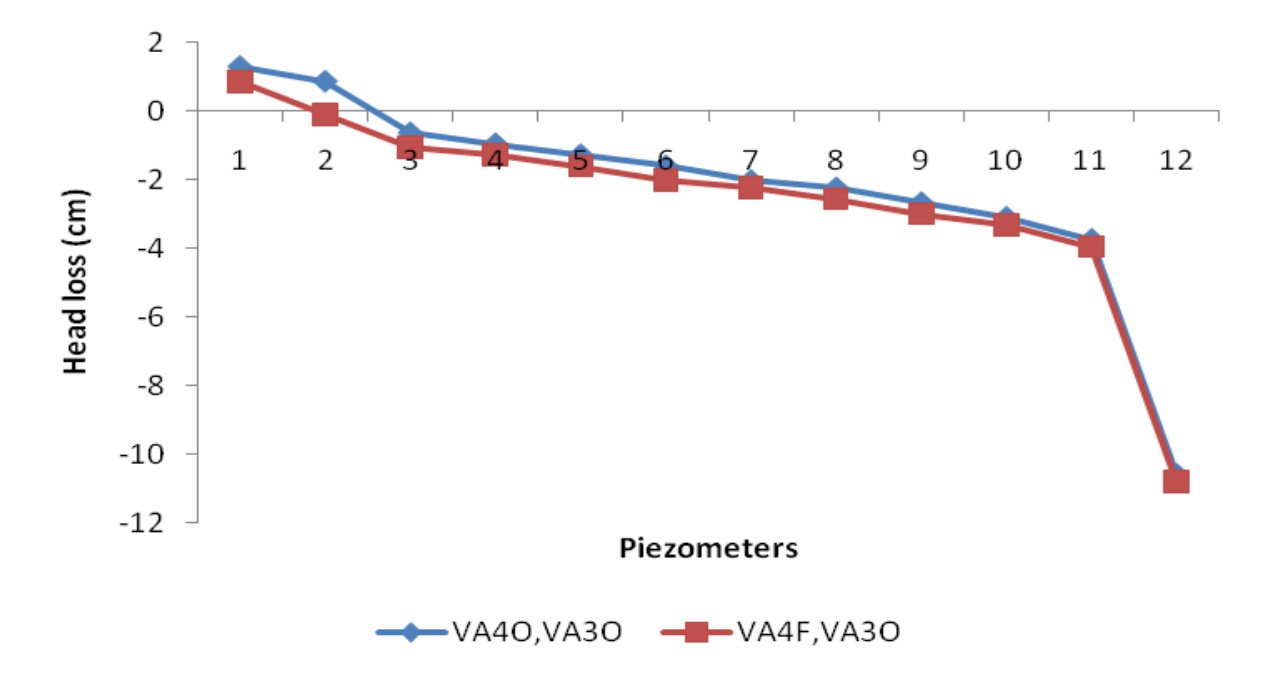

Figure 3. Evolution of the head loss according to the positions of the valves for the sand $\mathrm{N}^{\circ} 1$ with a flow rate of $30 \mathrm{~L} . \mathrm{h}^{-1}$, and a bentonite concentration of $0.1 \mathrm{~g} . \mathrm{L}^{-1}$

\subsubsection{Influence of the Flow}

For the flow, it has been found that by maintaining the position of the valves VA3O and VA4O (figure 4), the lowest head losses flow rate is $30 \mathrm{~L}^{-1} \mathrm{~h}^{-1}$, because when the flow increases, a large quantity of solids penetrates the filter per unit of time (Davies P.D, 2012), if the pressure increases, the pores clog more quickly just because of the number of particles that pass through the pores before clogging that become significantly faster (Wyss H.M. et al., 2006).

It has also been reported by Sendekie Z. \& Bacchin P. (2016) that the clogging process could also be delayed as the flow increases and that the increase in hydrodynamic force overcomes the repulsive forces for particle deposition and simultaneously breaks the inter-particulate links and the wall particle.

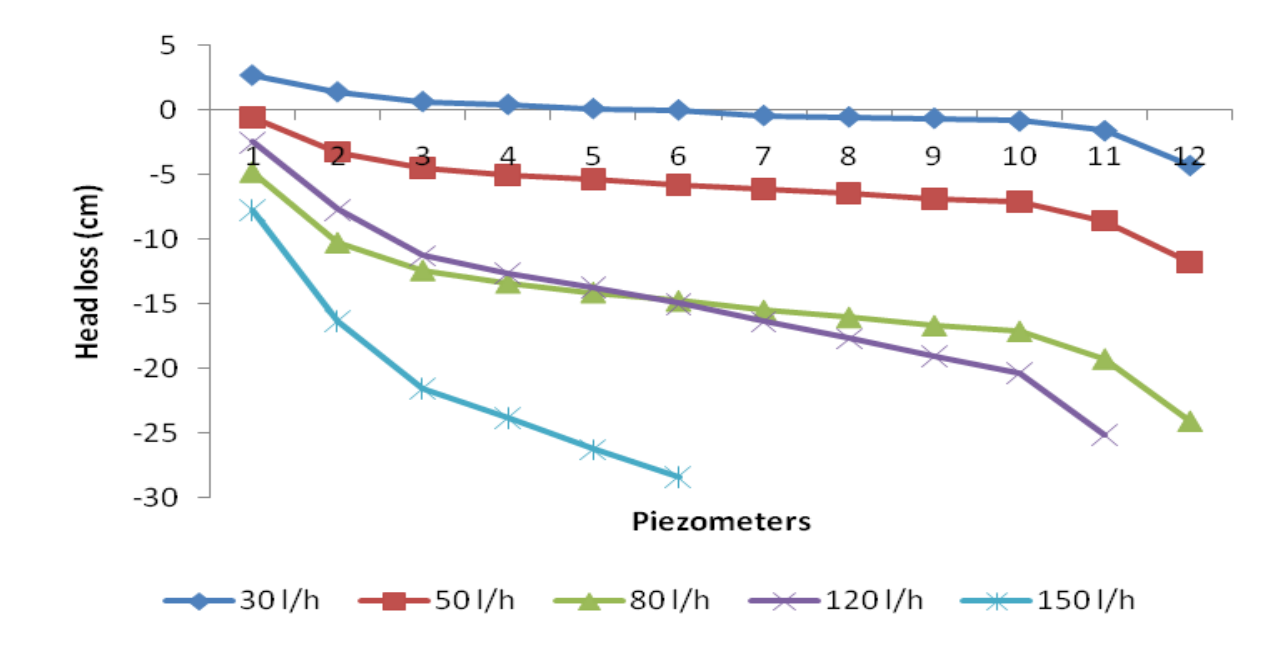

Figure 4. Evolution of the head loss according to the flows for the sand $\mathrm{N}^{\circ} 1$ with a bentonite concentration of $0.1 \mathrm{~g} . \mathrm{L}^{-1}$ 


\section{Macrothink}

\subsubsection{Influence of Suspended Matters}

As for the suspended matters, it has been found that for a flow rate of $30 \mathrm{~L}^{-1} \mathrm{~h}^{-1}$, the bentonite gives the lowest head loss (figure 5). This fact is because the bentonite is finer than the lime, which generates a smaller clogging compared to that of lime. The progressive clogging of the interstices of the material leads to an increase in the head loss; the quality water treated has an impact on the level of fouling (Touila Y. et al., 2014). However, another study by Veerapaneni S. \& Wiesner M., (1997), states that for small particles, its transport has a relatively greater diffusive component resulting in more porous deposits and that for large particles, the trajectory is more ballistic, and the formed deposits are more compact of all. As a result, for the same mass of deposited particles, deposits formed at lower fluid velocities occupy more porous space in the filter bed, resulting in greater drag loss of the fluid, resulting in the greater head loss.

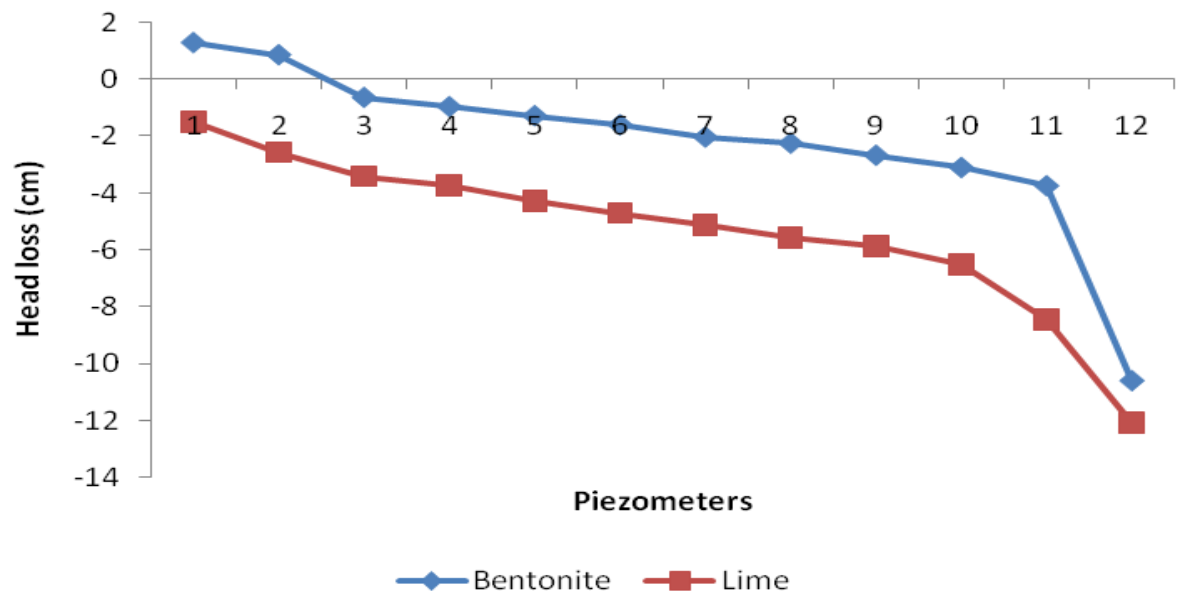

Figure 5. Evolution of the head loss according to the suspended matters for the sand $\mathrm{N}^{\circ} 1$ with a flow rate of $30 \mathrm{~L} . \mathrm{h}^{-1}$ and a bentonite/lime concentration of $0.1 \mathrm{~g} . \mathrm{L}^{-1}$

\subsubsection{Influence of the Concentration of Suspended Matters}

It was also found that with a flow rate of $30 \mathrm{~L}^{-\mathrm{h}^{-1}}$, the three types of sand give the lowest head loss for a concentration (lime/bentonite) of 0.1 g.L.-1 (figure 6) because the more the solution is concentrated, the more the particles accumulation on the filter layer is important. After a while, the porosity decreases with time and therefore an increase in the filter fouling, which may result from a mechanical clogging due to the settlement of the filter support and thus the reorganization of the solid skeleton of the filter layer which increases the head losses, the rate of accumulation of head loss in a filter strongly depends on the size of the particles in suspension and the size of the granular media (Boller M.A. \& Kavanaugh M.C., 1995 ; Touila Y. et al., 2014). 


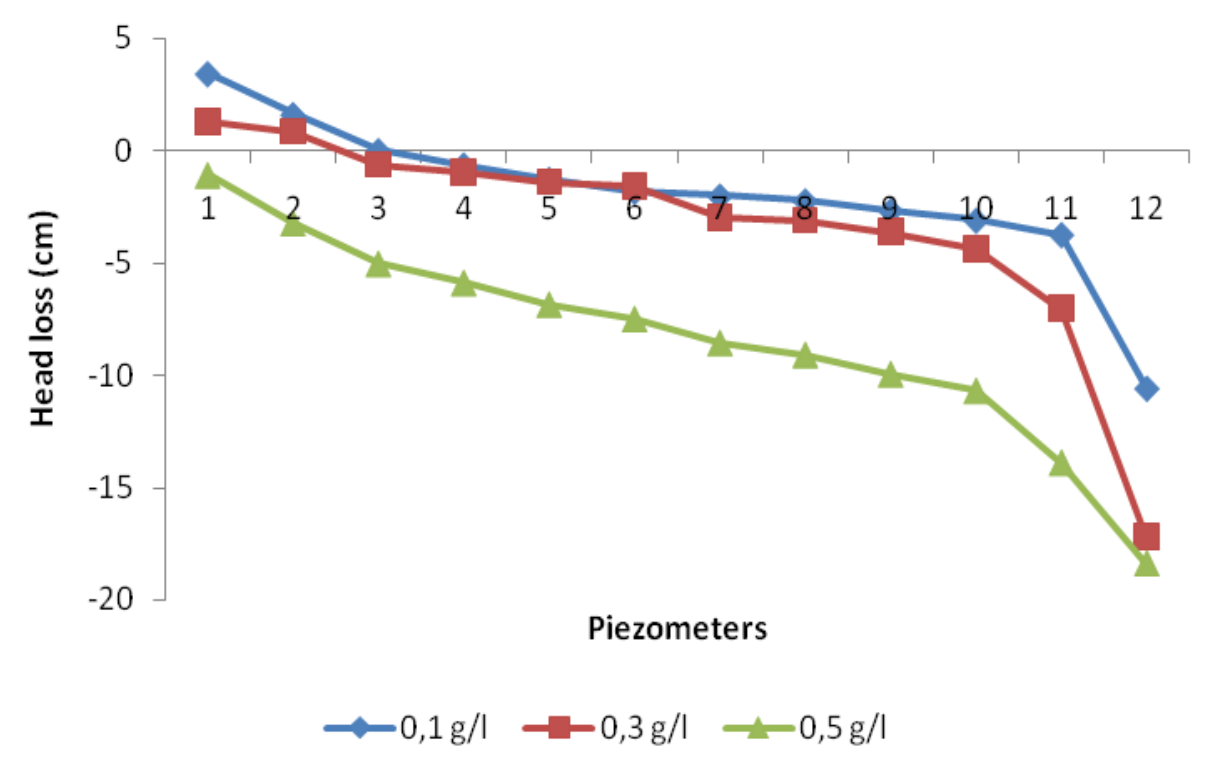

Figure 6. Evolution of the head loss according to the concentration of bentonite for the sand $\mathrm{N}^{\circ} 1$ with a flow rate of $30 \mathrm{~L} \cdot \mathrm{h}^{-1}$

\subsubsection{Influence of the Sand Granulometry}

It was also found that for high flow rates $\left(120 \mathrm{~L} \cdot \mathrm{h}^{-1}\right.$ and $\left.150 \mathrm{~L} \cdot \mathrm{h}^{-1}\right)$ the head losses were so great that they could not be measured by the twelve piezometers $(>-30 \mathrm{~cm})$, but also that for the three types of sand the flow rate of $150 \mathrm{~L} . \mathrm{h}^{-1}$ could not be reached even after a total opening of the valve VR1, for a concentration of bentonite and lime of 0.5 g.L.- What is explained by the trapping of suspended particles, which results in the reduction of the pore size, and consequently, the flow velocity decreases with the increase of the clogging level (Guofen H. et al., 2017). Therefore each blockage causes a small reduction in the permeability of the filter. Thus the clogging threshold is reached when the permeability disappears, and therefore the head loss across the filter increases, and, beyond a certain point, maintaining the flow becomes so difficult that the filter cycle is interrupted (Verma S. et al., 2017).

Regarding the influence of the particle size of the three types of sand, it was found that the sand $\mathrm{N}^{\circ} 3$ gives the lowest head loss then comes the sand $\mathrm{N}^{\circ} 1$ and finally the sand $\mathrm{N}^{\circ} 2$ (figure 7), it is explained by their granulometry, the fact that the sand $\mathrm{N}^{\circ} 3$ has the greatest that results in bigger grain size and thus a greater hole or porosity thereby a slower clogging. In contrast Boller M.A \& Kavanaugh M.C., (1995) found that filtration media having a high porosity give low initial head losses during filtration. However, it appears that the head losses increase due to the low deposit density. 


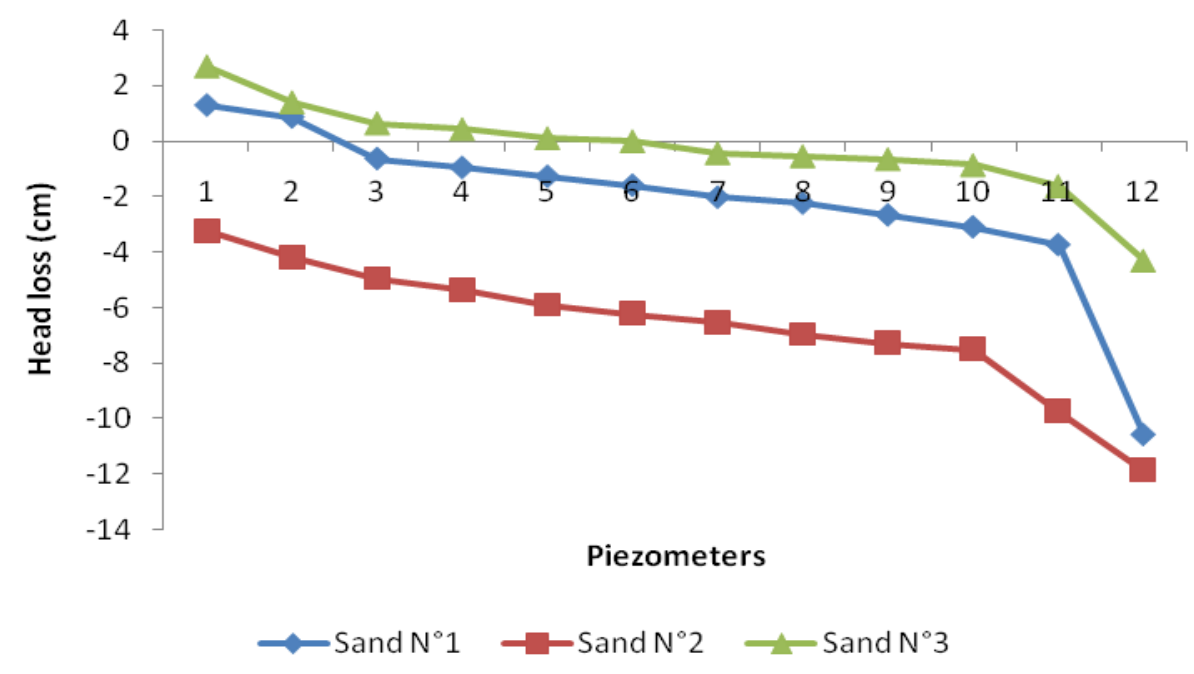

Figure 7. Evolution of the head loss according to the sand granulometry with a flow rate of $30 \mathrm{~L} . \mathrm{h}^{-1}$ and a concentration of bentonite of 0.1 g.L.

\subsection{Evolution of Turbidity}

The mechanism of purification, particles and organic pollutants removal and the reduction of turbidity are supposed to be through the surface deformation, and, it depends on the type of filter such as ; the height of the filter, the type and the particle size of the sand which influence the removal rate of the pollutants (Zaidun N.A., 2011).

The sand filter removal process consists of three steps; e.g. phase 1 characterized by the passage of particles through the filter, however, bridges can form a blockage of particles, at the end of this phase there is a rapid reduction of the effluent color with time reaching a low value, phase 2 which gives satisfactory quality to the effluent, and phase 3 the breakthrough stage (Eker O.F. et al., 2015)

\subsubsection{Influence of Suspended Matters Concentration}

It has been found that there is a reduction in turbidity for the three types of sands (figure 8). The decrease in color is most probably due to the total disappearance of the biodegradable and non-biodegradable organic matter, the colloidal matter, and the suspended matters (Ben Abbou M. \& El Haji M., 2014). This reduction occurs when the water passes through the Schmutzdecke, whose main process is the mechanical deformation of most of the suspended matter in a thin and dense layer in which the pores can be much smaller than one micron the suspend matters are retained by the filter (Linlin W. et al., 2011 ; Zaidun N.A., 2011).

But it has also been found that more the flow rate increases, the turbidity increases, because of the flux mass particle which can not overcome the particle/pore surface force and therefore the particles can not be deposited, this is referring to the critical density flux, and when the flow is strong, it is difficult for the particles to accumulate. Thus the particles are dragged towards the exit of the filter (Brans G. et al., 2007). It can be expected that the deposit withstands shear stresses only below a given limit; otherwise, it not adhere to the grains. There is also probably another upper limit above which existing deposits are washed away. 


\section{Macrothink

It has also been found that when the concentration of suspended matters (bentonite / lime) increases. There is also an increase in turbidity, the concentration of $0.1 \mathrm{~g} . \mathrm{L}^{-1}$ gives the lowest turbidity, and 0.5 g.L $\mathrm{L}^{-1}$ gives the greatest, because as the particles accumulate and more the water is concentrated the deposit causes the pore narrowing between the sand grains (Zahrim A.Y \& Hilal N., 2013), the flow path becomes narrower which significantly increases the shear rate, as a result, the particles are smashed and swept. Thus the greater the shear rate increases ; as well as the local velocity, the constraint applied to the particles becomes bigger, and it is more difficult to accumulate the particles that come off easily (Youngseok K. et al., 2017).

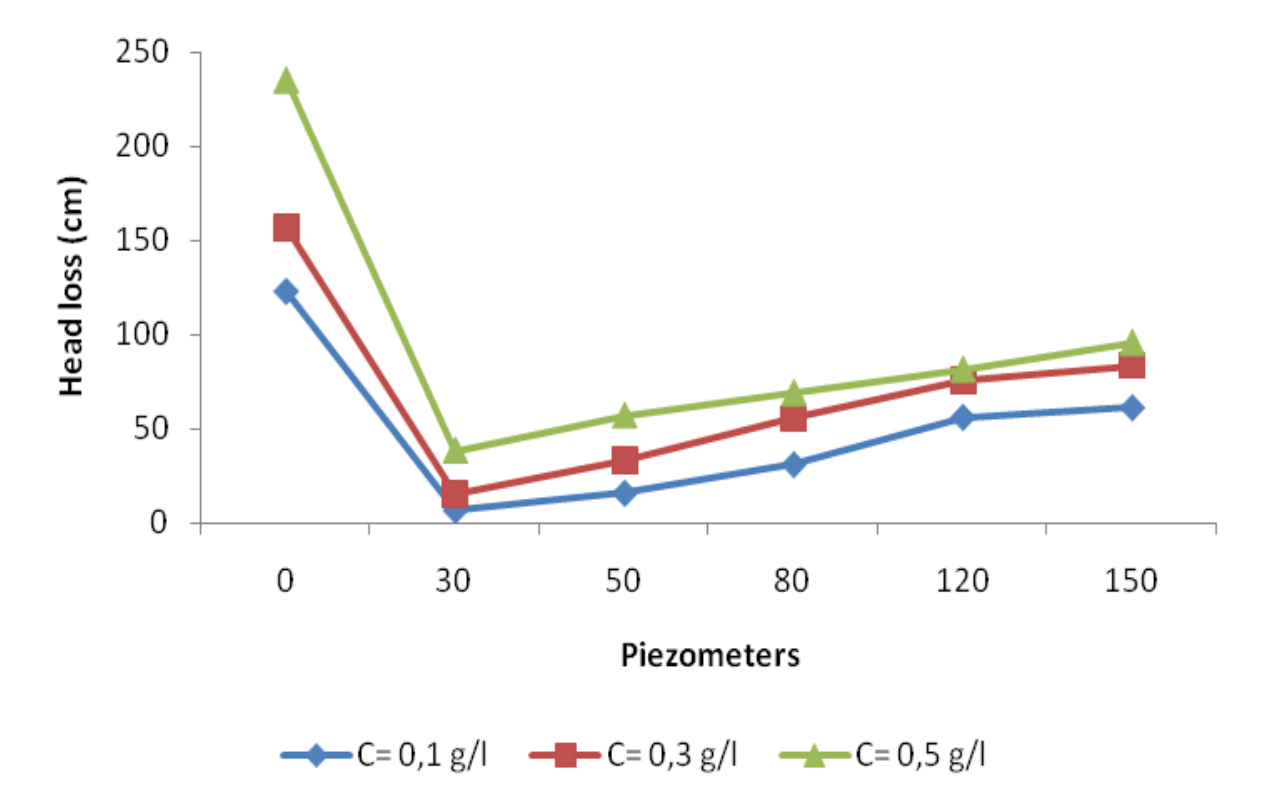

Figure 8 . Evolution of turbidity according to the bentonite concentration for the sand $\mathrm{N}^{\circ} 1$ with a flow rate of $30 \mathrm{~L} \cdot \mathrm{h}^{-1}$

\subsubsection{Influence of the Granulometry}

For each of the three types of sand the turbidity values change for the same concentration of lime and bentonite and the same flow (figure 9). The sand $\mathrm{N}^{\circ} 2$ gives the lowest turbidity then comes the sand $\mathrm{N}^{\circ} 1$ and finally the Sand $\mathrm{N}^{\circ} 3$. The lowest recorded values were $2.56,4.06$ and $8.66 \mathrm{NTU}$ respectively for a flow rate of $30 \mathrm{~L} . \mathrm{h}^{-1}$ and a lime concentration of $0.1 \mathrm{~g} . \mathrm{L}^{-1}$ for initial turbidity of $115 \mathrm{NTU}$ and the maximum values recorded were 81.1, 95.65 and 117.48 NTU respectively for a flow rate of $150 \mathrm{~L} . \mathrm{h}^{-1}$ and a bentonite concentration of $0.5 \mathrm{~g} . \mathrm{L}^{-1}$ for initial turbidity of 220 NTU.

Sand $\mathrm{N}^{\circ} 2$ gives the best results because it has the smallest grain size, because the smaller the grain size, the smaller the pore size, and the pore size distribution is also related to the grain size distribution (Chang J.S. et al., 2008), which allows it better retention of the particles thus a good turbidity reduction of the water, then comes the sand $\mathrm{N}^{\circ} 1$ and the sand $\mathrm{N}^{\circ} 3$ with greater granulometry. 


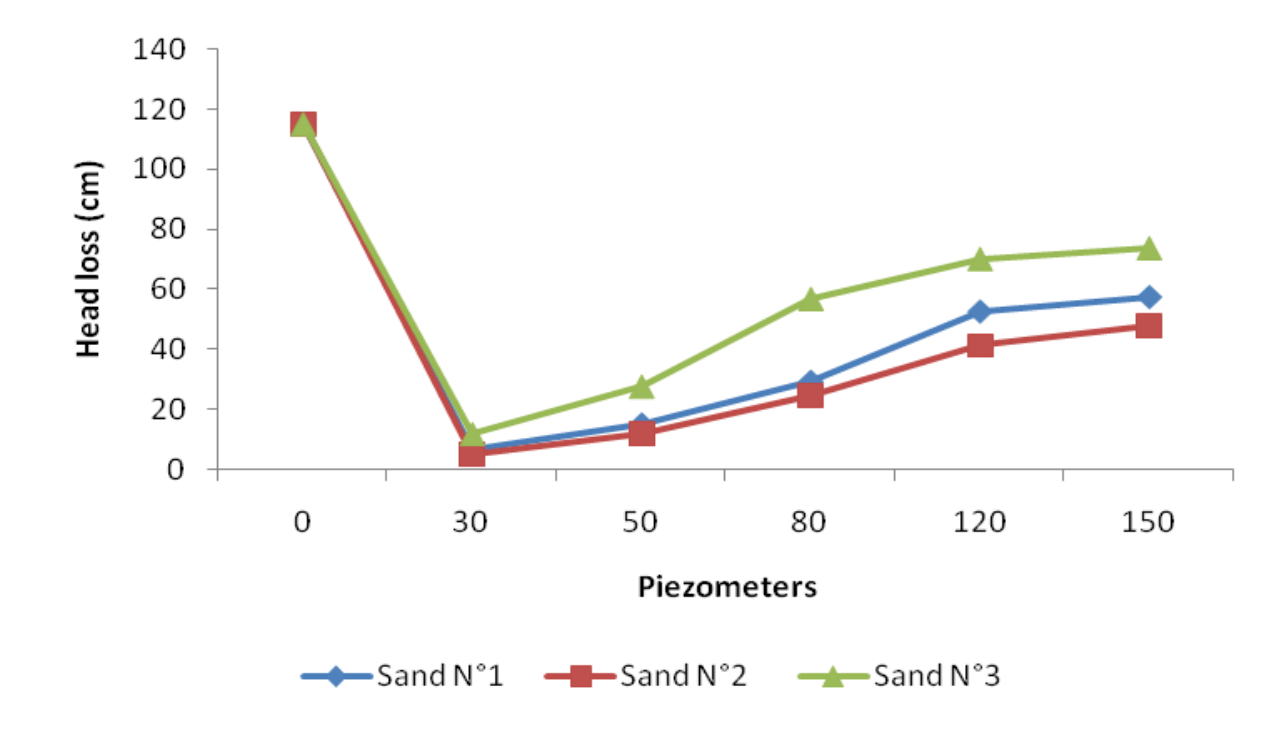

Figure 9. Evolution of turbidity according to the sand granulometry for a bentonite concentration of $0.1 \mathrm{~g} . \mathrm{L}^{-1}$ with a flow rate of $30 \mathrm{~L} . \mathrm{h}^{-1}$

\subsubsection{Influence of Suspended Matters}

It has been observed that for the same concentrations (lime/bentonite), the lime sample gives higher turbidity than that of the bentonite, but on the other hand, after filtration, lower turbidity is obtained for the lime sample (figure 10). This fact occurs because the bentonite is smaller than lime. Larger particles are easier to deposit in the pores, decreasing permeability and shrinking the porous channel. Meanwhile, finer particles can lead to less severe blocking than coarser particles, and subsequently cause a higher concentration in the outlet (Quansheng L. et al., 2015) and thus higher turbidity. As a result, as the particle size increases, it is more difficult to detach the particles once they are attached to the surface of the filter grain.

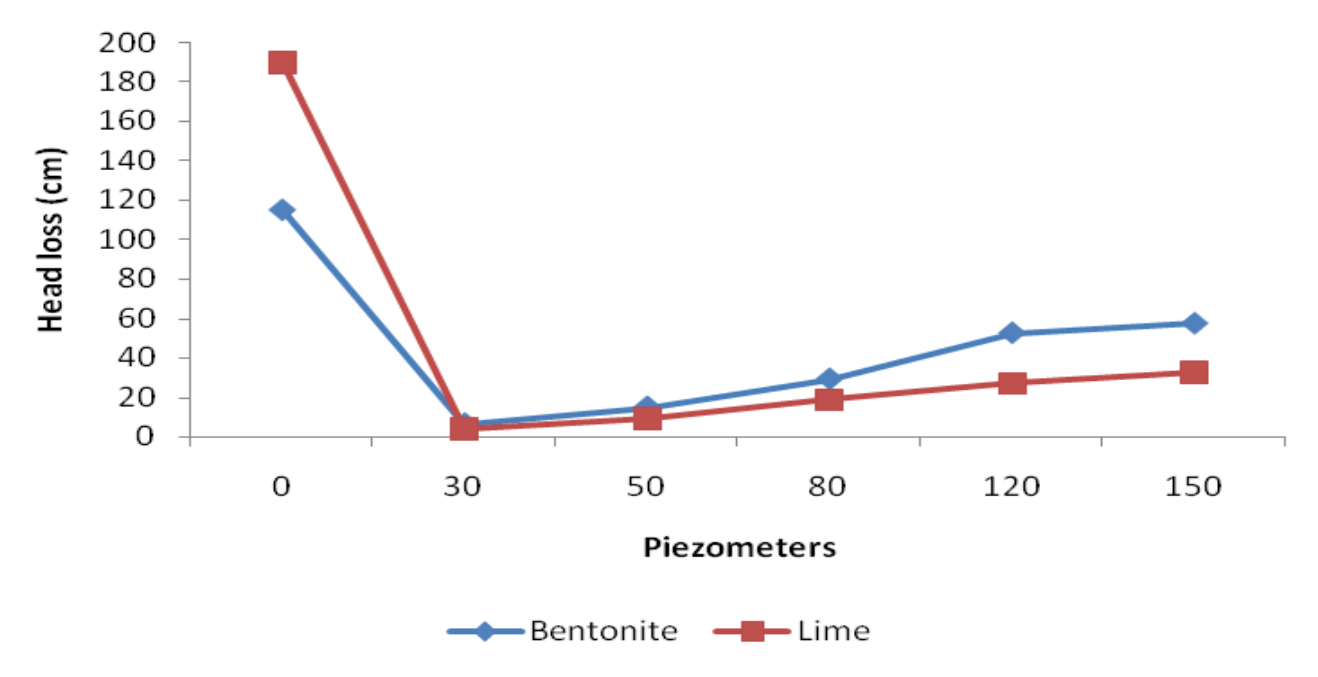

Figure 10. Evolution of turbidity according to the type of suspended matters for the sand $\mathrm{N}^{\circ} 1$ with a flow rate of $30 \mathrm{~L} . \mathrm{h}^{-1}$ and a bentonite/lime concentration of $0.1 \mathrm{~g} . \mathrm{L}^{-1}$ 


\section{Conclusion}

Several factors influence the head loss. It was found that when the pressure exerted on the filter increases and the flow increases, the clogging occurs more quickly due to a large number of solids entering the filter.

The size of the particles contained in the water and its concentration influence the head losses. We have seen it when using two different types of suspended matters of different sizes with increasing concentrations, it was found that as the size of the particles as well as the concentration increases the head losses increase, this is due to the retention of the coarse particles within the filter medium and the higher the concentration, the more particles are retained.

The particle size of the filter medium is also a parameter which has a great influence on the head losses, after having tested three types of sand of different particle sizes, it has been found that when the granulometry is small, this results in more or less weak grain size and therefore a hole or porosity less important which generates a fast clogging.

Several parameters also influence. There is a reduction in turbidity by sand filtration; however, when the flow increases, the turbidity also increases, because it is difficult for the particles to accumulate due to the particle, pore surface force, so that the particles have been dragged to the filter outlet.

It has been found that when two different types of suspended matter with different concentrations, an increase in turbidity are observed for the thinnest suspended matters because it leads to less serious blocking than the coarser particles, and generates a higher concentration at the outlet. For high concentrations of suspended matter, we have noticed that as the particles accumulate, the flow path becomes narrower, which increases the shear rate ; as a result, the particles are broken and swept toward the filter output, and therefore the turbidity increases.

Regarding the influence of particle size on turbidity, the smaller the grains, the smaller the pore openings, which allows better retention of particles, so a good turbidity reduction of the water.

This work allows us to highlight both the importance and the complexity of several factors influencing the head losses as well as the turbidity. This complexity is expressed by the fact that only a few parameters can be controlled, such as granulometry and filtration rate. However, the particle size and the concentration of water at the filter inlet can be controlled.

These parameters must be taken into account when designing a filtration system on filter media for its proper functioning and longevity.

\section{References}

AFNOR. (1997). Recueil des normes françaises (Compilation of french regulations).

Aloo, B. N., Mulei, J., \& Mwamburi, A. L. (2014). Slow Sand Filtration of Secondary Sewage Effluent: Effect of Sand Bed Depth on Filter Performance. IJIRSET, 3(8). 
Ben, A. M., \& El, H. M. (2014). Treatments by electrocoagulation- filtration of uncontrolled Leachate discharge from the city of Taza and re-use in the germination of sorghum and alfalfa. International Journal of Innovation and Applied Studies, 9(1), 355-366.

Boller, M. A., \& Kavanaugh, M. C. (1995). Particle characteristics and headloss increase in granular media filtration. Wat. Res, 29(4), 1139-1149. https://doi.org/10.1016/0043-1354(94)00256-7

Brans, G., Van Dinther, A., Odum, B., Schroen, C. G. P. H., \& Boom, R. M. (2007). Transmission and fractionation of micro-sized particle suspensions. J. Membr Sci, 290(1-2), 230. https://doi.org/10.1016/j.memsci.2006.12.045

Campos, L. C., Su, M. F. J., Graham, N. J. D., \& Smith, S. R. (2002). Biomass development in slow sand filters. Water Research, 36(18), 4543-4551. https://doi.org/10.1016/j.memsci.2006.12.045

Chang, J. S., Vigneswaran, S., Kandasamy, J. K., \& Tsai, L. J. (2008). Effect of pore size and particle size distribution on granular bed filtration and microfiltration. Separation Science and Technology, 43(7), 2008. https://doi.org/10.1080/01496390801974605

Davies, P. D. (2012). Alternative filter media in rapid gravity, filtration of potable water. Doctoral thesis Loughborough University. https://doi.org/10.1080/01496390801974605

Eker, O. F., Camci, F., \& Jennions, I. K. (2015). Physics-based prognostic modellinf of filter clogging phenomena. Mechanical system and signal processing. https://doi.org/10.1080/01496390801974605

Ephrem, G. (2015). Review on Slow Sand Filtration in Removing Microbial Contamination and Particles from Drinking Water. American Journal of Food and Nutrition, 3(2),47-55.

Georgieva, K., Dijkstra, D. J., Fricke, H., \& Willen Bacher, N. (2010). Clogging of microchannels by nano-particles due to hetero-coagulation in elongational flow. Journal of $\begin{array}{llll}\text { Colloid and Interface } \quad \text { Science, } & 352(2010),\end{array}$ https://doi.org/10.1080/01496390801974605

Guofen, H., Jun, K., Yuyu, J., \& Man, L. (2017). Influence of clogging and resting processes on flow patterns in vertical flow constructed wetlands. Science of the Total Environment. https://doi.org/10.1016/j.scitotenv.2017.10.113

Liénard, A., Guellaf, H., \& Boutin, C. (2001). Choice of the sand for sand filters used for secondary treatment of wastewater. Water Science \& Technology, 44(2-3), 189-196. https://doi.org/10.2166/wst.2001.0769

Linlin, W., Xuan, Z., \& Meng, Z. (2011). Removal of dissolved organic matter in municipal effluent with ozonation, slow sand filtration and nanofiltration as high quality pre-treatment option for artificial groundwater recharge. Chemosphere 83(5), 693-699.

Mays, C. D., \& Hunt, J. R. (2005). Hydrodynamic aspects of particle clogging in porous media. Environ. Sci. Technol, 39(2), 577-584. 


\section{Macrothink}

Aquatic Science and Technology

ISSN 2168-9148 2020, Vol. 8, No. 2

Quansheng, L., Xianze, C., Chengyuan, Z., \& Shibing, H. (2015). Experimental investigation of suspended particles transport through porous media: particle and grain size effect. Environmental Technology.

Rodgers, M., Healy, M. G., \& Mulqueen, J. (2005). Organic carbon removal and nitrification of high strength wastewaters using stratified sand filters. Water Research, 39, 3279-3286.

Sendekie, Z., \& Bacchin, P. (2016). Colloidal Jamming Dynamics in Microchannel Bottlenecks. Langmuir, American chemical society, 32(6), 1478-1488.

Tansel, B., \& Vilar, F. (2005). Enhancement of media filter performance with coagulant use for treatment of diesel oil contaminated surface water. Desalination, 173(2005), 69-76.

Touila, Y., Gherairia, Y., Issaadib, R., \& Amranec, A. (2014). Biological filtration on sand of dunes - Filters fouling. Energy Procedia, 50(2014), 471-478.

Veerapaneni, S., \& Wiesner, M. (1997). Deposit morphology and head loss development in porous media. Environmental science \& technology, 31(10).

Verma, S., Daverey, A., \& Sharma, A. (2017). Slow sand filtration for water and wastewater treatment - a review. Environmental Technology Reviews, 6(1), 47-58.

Wyss, H. M., Blair, D. L., Morris, J. F., Stone, H. A., \& Weitz, D. A. (2006). Mechanism for clogging of microchannels. Physical review, 74(6).

Youngseok, K., Kyung, H. A., \& Seung, J. L. (2017). Clogging mechanism of poly(styrene) particles in the flow through a single micro-pore. Journal of Membrane Science. https://doi.org/10.1016/j.memsci.2017.04.010

Zahrim, A. Y., \& Hilal, N. (2013). Treatment of highly concentrated dye solution by coagulation/floculation-sand filtration and nanofiltration. Water resources and industry, 3(2013), 23-34.

Zaidun, N. A. (2011). The effect of sand filter characteristics on removal efficiency of organic matter from grey water. Al-Qadisiya Journal For Engineering Sciences, 4(2).

\section{Copyrights}

Copyright for this article is retained by the author(s), with first publication rights granted to the journal.

This is an open-access article distributed under the terms and conditions of the Creative Commons Attribution license (http://creativecommons.org/licenses/by/4.0/) 